\title{
Food choice motives of Royal Navy personnel
}

\author{
A.M. Shaw ${ }^{1,2}$, T. Davey ${ }^{1}$, A.J. Allsopp ${ }^{1}$, E.L. Parsons ${ }^{2,3}$, S.A. Wootton ${ }^{2,3}$ and J.L. Fallowfield ${ }^{1}$ \\ ${ }_{1}^{1}$ Institute of Naval Medicine, Alverstoke, Gosport, PO12 2DL; ${ }^{2}$ Human Development and Health Academic Unit, \\ Faculty of Medicine, University of Southampton, Southampton, SO17 1BJ; and ${ }^{3}$ NIHR Southampton Biomedical \\ Research Centre, Southampton Centre for Biomedical Research, Southampton General Hospital, Southampton,
} SO16 $6 Y D$

The United Kingdom Armed Forces are not exempt from the obesity epidemic ${ }^{(1)}$. This is of concern due to the health, occupational and economic risks that it poses. Poor dietary habits and physical inactivity have traditionally been identified as major factors associated with overweight and obesity ${ }^{(2)}$, where understanding the factors influencing an individual's food choice decisions may help inform interventions to improve dietary behaviours and hence tackle obesity. Thus, the present study investigated the motives for food choice of Royal Navy (RN) personnel.

A stratified convenience sample of $n 600 \mathrm{RN}$ personnel (males 52\%, females $48 \%$ ), mean (SD) age 29 (8) years ( $n 201$ aged 18-24 years, $n 246$ aged $25-34$ years, $n 153 \geqslant 35$ years) volunteered to participate in the study between May 2012 and January 2013. Participants completed a motives for food choice questionnaire ${ }^{(3)}$, demographics questionnaire and had their height, body weight and waist circumference measured. Risk of obesity-related diseases, according to the National Institute for Health and Care Excellence (NICE) was determined ${ }^{(4)}$

The highest rated motives for food choice were Sensory Appeal, Health and Price. The lowest rated factors were Familiarity and Ethical Concern. Female participants were more likely to be motivated by Sensory Appeal, Weight Control, Convenience and Mood compared with male participants $(\mathrm{P}<0.05$; Table 1$)$.

Table 1.

\begin{tabular}{|c|c|c|c|c|c|c|c|c|c|c|}
\hline \multirow[b]{2}{*}{ Scale } & \multicolumn{2}{|c|}{ Males } & \multicolumn{2}{|c|}{ Females } & \multicolumn{2}{|c|}{ 18-24 years old } & \multicolumn{2}{|c|}{ 25-34 years old } & \multicolumn{2}{|c|}{$\geqslant 35$ years old } \\
\hline & Mean & SD & Mean & $\overline{\mathrm{SD}}$ & Mean & $\overline{\mathrm{SD}}$ & Mean & $\overline{\mathrm{SD}}$ & Mean & $\mathrm{SD}$ \\
\hline Health & 2.7 & 0.7 & $2 \cdot 8$ & $0 \cdot 6$ & 2.7 & 0.7 & $2 \cdot 7$ & 0.7 & $2 \cdot 7$ & 0.6 \\
\hline Mood & $2 \cdot 0^{*}$ & 0.7 & $2 \cdot 1$ & $0 \cdot 6$ & $2 \cdot 1+$ & 0.7 & $2 \cdot 0$ & 0.6 & 1.9 & 0.6 \\
\hline Convenience & $2 \cdot 3^{*}$ & 0.7 & $2 \cdot 6$ & $0 \cdot 7$ & $2 \cdot 5$ & $0 \cdot 8$ & $2 \cdot 4$ & 0.7 & $2 \cdot 4$ & 0.7 \\
\hline Sensory Appeal & $2 \cdot 7^{*}$ & $0 \cdot 6$ & $2 \cdot 9$ & $0 \cdot 6$ & $2 \cdot 7+$ & $0 \cdot 6$ & $2 \cdot 7 \dagger$ & $0 \cdot 6$ & $2 \cdot 9$ & 0.6 \\
\hline Natural Content & $2 \cdot 3$ & $0 \cdot 8$ & $2 \cdot 4$ & $0 \cdot 8$ & $2 \cdot 1+t$ & $0 \cdot 8$ & $2 \cdot 4$ & $0 \cdot 8$ & $2 \cdot 5$ & $0 \cdot 8$ \\
\hline Price & $2 \cdot 6$ & 0.7 & $2 \cdot 5$ & $0 \cdot 8$ & $2 \cdot 6$ & $0 \cdot 8$ & $2 \cdot 5$ & 0.7 & $2 \cdot 5$ & 0.7 \\
\hline Weight Control & $2 \cdot 2^{*}$ & 0.8 & $2 \cdot 6$ & $0 \cdot 8$ & $2 \cdot 4$ & $0 \cdot 9$ & $2 \cdot 4$ & 0.8 & $2 \cdot 5$ & 0.7 \\
\hline Familiarity & 1.8 & $0 \cdot 6$ & 1.8 & $0 \cdot 6$ & 1.9 & 0.6 & 1.8 & $0 \cdot 6$ & 1.8 & 0.6 \\
\hline Ethical Concern & $1 \cdot 5$ & $0 \cdot 7$ & 1.6 & $0 \cdot 6$ & $1.4 \div$ & 0.6 & 1.5 & 0.6 & 1.7 & 0.7 \\
\hline
\end{tabular}

$* \mathrm{P}<0.05$ difference to females; $\dagger \mathrm{P}<0.05$ difference to $\geqslant 35$ year age group; $\ddagger \mathrm{P}<0.05$ difference to $25-34$ year age group.

Participants aged 18-24 years old rated Mood higher and Sensory Appeal, Ethical Concern and Natural Content lower compared with participants aged $\geqslant 35$ years old $(\mathrm{P}<0.05$; Table 1$)$. Participants in the 25-34 year age group rated Sensory Appeal lower and Natural Content higher compared with participants in the $\geqslant 35$ and $18-24$ year age groups, respectively $(\mathrm{P}<0 \cdot 05$; Table 1$)$.

Participants classified as being at any increased risk of obesity-related diseases rated Health lower compared with participants at no increased risk $(2.6[0 \cdot 7]$ vs. $2 \cdot 8[0 \cdot 7], \mathrm{P}<0 \cdot 05)$.

In conclusion, the findings from the present study suggest that interventions to improve the dietary behaviours of RN personnel should be targeted based on demographic factors and NICE risk classification, rather than adopting a "one size fits all" approach.

(C) Crown Copyright (MOD) 2018: Published with the permission of the Controller of HMSO.

1. Wood P (2007) Dstl Report No.: TR27252. Dstl, Farnborough, UK

2. Prentice AM \& Jebb SA (1995) BMJ. 311, 437.

3. Steptoe A, Pollard RM \& Wardle J (1995) Appetite. 25(3), 267-284.

4. NICE (2014) NICE guidelines CG189. NICE, London, UK. 